\title{
A Relação Entre o Princípio Educativo de Gramsci com a Educação Profissional no Ensino MÉdio InTEgrado ao Proeja
}

\author{
THE RELATIONSHIP BETWEEN GRAMSCI'S EDUCATIONAL PRINCIPLE AND \\ PROFESSIONAL EDUCATION IN HIGH SCHOOL INTEGRATED WITH PROEJA
}

\author{
LA RELACIÓN ENTRE EL PRINCÍPIO EDUCATIVO DE GRAMSCI Y LA EDUCACIÓN \\ PROFESIONAL EN LA ESCUELA SECUNDARIA INTEGRADA CON PROEJA
}

\section{Silvia Maria dos Santos \\ Stering \\ (iD) 9}

Pós-doutora em Educação (UFMT)

Doutora em Educação (UNESP -

Rio Claro/SP)

Pedagoga no Instituto Federal de

Mato Grosso (PROEN/IFMT)

silvia.stering@ifmt.edu.br

\section{Marilene Luzia Pinto de Carvalho \\ (iD) 9}

Especialista em Educação do

Campo

Professora da Rede Estadual de

Educação de Mato Grosso

(SEDUC-MT)

marilenevendedora@hotmail.com

\section{Ricardo de Assis \\ (iD) 9}

Especialista na área de História, com ênfase na História de Mato Grosso

Professor da Rede Estadual de Educação de Mato Grosso

(SEDUC-MT)

ricardinhoassis13@gmail.com

\section{Marilda Domingas Pinto \\ (iD) 9}

Especialista em Educação

Interdisciplinar

Professor da Rede Estadual de

Educação de Mato Grosso

(SEDUC-MT)

marildadomingas77@ hotmail.com

\section{Resumo}

A Educação Profissional e Tecnológica- EPT, na visão de Gramsci, no contexto da formação escolar na modernidade, se configura como expressão distorcida e limitada quanto às funções e formas da instrução profissional, da relação entre a separação desinteressada formativa e a profissional. Contudo, na busca pela superação das desigualdades sociais impostas pelo mundo do capital, a EPT surge como uma possibilidade para conciliar o rigor próprio da fábrica e o exercício reflexivo da exigência humanística, como possibilidade de realização da formação do trabalhador, para realizar uma educação vinculada aos objetivos estratégicos de um projeto similar à proposição de Gramsci, no que se refere à Escola Unitária, que busque não apenas a inclusão no contexto de uma sociedade desigual, mas a construção de uma nova sociedade, fundada na igualdade política, econômica e social. O artigo tem por objetivo evidenciar a relação entre o princípio educativo de Gramsci com a Educação Profissional no Ensino Médio Integrado ao Proeja. Trata-se de uma pesquisa bibliográfica documental. A investigação aponta que a sociedade atual, carece de uma escola que prepare sim para o mundo do trabalho, porém em uma perspectiva focada na democracia e na justiça social, capaz de compreender o trabalho como princípio educativo.

Palavras-chave: Educação Profissional e Tecnológica. Trabalho como Princípio Educativo. Formação do Trabalhador.

Recebido em: 24 de fevereiro de 2021.

Aprovado em: 14 de abril de 2021.

Como citar esse artigo (ABNT):

STERING, Silvia Maria dos Santos et al. A relação entre o princípio educativo de Gramsci com a educação profissional no ensino médio integrado ao Proeja. Revista Prática Docente, v. 6, n. 1, e017, 2021.

http://doi.org/10.23926/RPD.2021.v6.n1.e017.id1027 


\section{Abstract}

Professional and Technological Education - EPT, in the view of Gramsci, in the context of school education in modern times, is configured as a distorted and limited expression regarding the functions and forms of professional instruction, the relationship between the disinterested formative and professional separation. However, in the search for overcoming the social inequalities imposed by the world of capital, EPT emerges as a possibility to reconcile the strictness of the factory and the reflexive exercise of the humanistic requirement, as a possibility of carrying out worker training, to carry out a linked education to the strategic objectives of a project similar to Gramsci's proposal, with regard to the Unitary School, which seeks not only inclusion in the context of an unequal society, but the construction of a new society, founded on political, economic and social equality. The article aims to highlight the relationship between Gramsci's educational principle and Professional Education in High School Integrated with Proeja. This is a documentary bibliographic search. The investigation points out that today's society lacks a school that does prepare for the world of work, but in a perspective focused on democracy and social justice, capable of understanding work as an educational principle.

Keywords: Professional and Technological Education. Work as an Educational Principle. Worker Training.

\section{Resumen}

Educación Profesional y Tecnológica - EPT, a juicio de Gramsci, en el contexto de la educación escolar en los tiempos modernos, se configura como una expresión distorsionada y limitada respecto a las funciones y formas de la instrucción profesional, la relación entre el desinteresado formativo y la separación profesional. Sin embargo, en la búsqueda de la superación de las desigualdades sociales impuestas por el mundo del capital, el EPT surge como una posibilidad de conciliar el rigor de la fábrica y el ejercicio reflexivo de la exigencia humanística, como posibilidad de realizar la formación del trabajador, para llevar a cabo una educación vinculada a los objetivos estratégicos de un proyecto similar a la propuesta de Gramsci, en lo que respecta a la Escuela Unitaria, que busca no solo la inclusión en el contexto de una sociedad desigual, sino la construcción de una nueva sociedad, fundamentada en temas políticos, económicos y sociales. igualdad. El artículo tiene como objetivo resaltar la relación entre el principio educativo de Gramsci y la Educación Profesional en Bachillerato Integrado con Proeja. Se trata de una búsqueda bibliográfica documental. La investigación apunta que la sociedad actual carece de una escuela que sí se prepare para el mundo del trabajo, pero en una perspectiva centrada en la democracia y la justicia social, capaz de entender el trabajo como un principio educativo.

Palabras clave: Educación Profesional y Tecnológica. El trabajo como principio educativo. Formación de trabajadores. 


\section{INTRODUÇÃo}

A atividade relativa ao trabalho consiste naquela que possibilita ao sujeito criar algo em benefício de outro e de si mesmo, a partir de prescrições consolidadas no conhecimento instituído via leis, ciência, normas e da criação/inovação do conhecimento investido na experiência pessoal. Essa junção objetiva origina o trabalho e o produto resultante dele em duas instâncias, sendo a atualização da prescrição/conhecimento instituído e a atualização das relações sociais culturais, comunicacionais e políticas.

Diante do exposto, a escola tem como tarefa preparar técnicos para que tenham alguns diferenciais, como a criticidade de pensamento e a capacidade de iniciativa, uma vez que, via essa última, o indivíduo não mais executa ordens, simplesmente, mas faz parte do processo produtivo de forma proativa. Além disso, há uma preocupação em todo o ensino de base com a formação de um alicerce sólido para a construção da cidadania do indivíduo, incluindo a questão da consciência política, social e, acima de tudo, tornando-o capaz de ter um posicionamento ético, proposição defendida por Gramsci mediante desenvolvimento da Escola Unitária e da qual compartilhamos.

O ideário de Gramsci é perpassado pelo pensamento marxista. Assim como Marx, Gramsci compreendia as origens materiais e históricas e o antagonismo presentes na luta de classes, destacando a importância da luta pela consciência da classe proletária contra a exploração burguesa. De origem humilde, desde muito cedo Gramsci teve muita dificuldade para estudar, o que leva a inferir que daí nasce o seu interesse pela educação na perspectiva de possibilidade de transformação de vidas.

A partir da leitura dialética dos escritos de Marx, Gramsci passou a visualizar na escola pública a possibilidade da obtenção da consciência de classe, vinculando a ideia do processo de trabalho como um princípio educativo. Realizou estudos referentes ao Estado capitalista e a ruptura que estabeleceu com teorias dominantes que influenciavam o movimento socialista da Itália.

Tendo em vista a proximidade do pensamento de Gramsci com os preceitos da Educação Profissional e Tecnológica, este estudo tem por objetivo evidenciar a relação entre o princípio educativo de Gramsci com a Educação Profissional no Ensino Médio Integrado ao Proeja a fim de aliar a proposta de Escola Unitária de Gramsci para a educação como ferramenta principal de evolução das classes proletárias. 
Nos dias atuais, é possível identificar e analisar, no contexto da educação brasileira, marcas a partir da teoria educacional proposta por Gramsci, que pode ser compreendido como filósofo, educador, político e intelectual. Esta análise será realizada a partir do PROEJA Programa Nacional de Integração da Educação Profissional com a Educação Básica, na Modalidade de Educação de Jovens e Adultos, que se constitui em uma política social focalizada, estando em consonância com as estratégias prescritas pela atual política estatal brasileira para o crescimento econômico e a redução da pobreza. Neste sentido, para a inclusão dos alunos do PROEJA nesta realidade que, segundo o Documento Base, se impõe, faz-se necessária a qualificação para além de uma formação profissional técnica, pretendendo:

[...] a formação humana, no seu sentido lato, com acesso ao universo de saberes e conhecimentos científicos e tecnológicos produzidos historicamente pela humanidade, integrada a uma formação profissional que permita compreender o mundo, compreender-se no mundo e nele atuar na busca de melhoria das próprias condições de vida e da construção de uma sociedade socialmente justa. A perspectiva precisa ser, portanto, de formação na vida e para a vida e não apenas de qualificação do mercado ou para ele (BRASIL, 2007, p. 17).

A qualificação pretendida pelo PROEJA requer a articulação entre os conhecimentos gerais e os profissionalizantes, uma vez que se busca mediante processo formativo desenvolver saberes com capacidade para possibilitar aos alunos do PROEJA a mobilidade para mudarem de uma ocupação a outra, melhorando suas próprias condições de vida.

\section{A Escola Unitária como Proposta Educacional de Gramsci}

Militante, Antônio Gramsci (1891-1937) exerceu importante empenho na fundação do Partido Comunista Italiano (1921). Em 1926 foi preso pela polícia fascista e, mesmo com imunidade parlamentar, foi condenado a cinco anos de confinamento e, no ano seguinte, a mais vinte anos de prisão em Turin. Pouco tempo depois de conseguir sua liberdade condicional, Gramsci morre em Roma, aos 46 anos. O tempo em que permaneceu na prisão foi um tempo de muita reflexão. Gramsci escreveu mais de trinta cadernos de história e análise, intitulados como Cadernos do Cárcere e Cartas do Cárcere, com registros do nacionalismo italiano, com foco na teoria crítica e educacional.

As teorias de Gramsci eram fruto da associação das ideias de Marx e Maquiavel, em que o autor fazia uma analogia ao Partido Comunista como o novo Príncipe. Gramsci acreditava que a tomada do poder só aconteceria a partir de mudanças de mentalidade. Em uma perspectiva de revolução social, Gramsci via os intelectuais como os principais agentes dessas mudanças, e a escola como um dos seus instrumentos mais importantes para a conquista da cidadania. 
A compreensão de Gramsci quanto hegemonia se configura como o domínio de uma dada classe social sobre o conjunto da sociedade. Tal domínio pode ser exercido pela força ou pelo consenso; na mesma medida em que tal força pode também ser exercida pelas instituições políticas, jurídicas e educacionais, e o consenso via liderança ideológica. Gramsci vinculou o pensamento de Marx ao tempo presente. Enquanto Marx via as instituições do Estado como reprodutoras, incluindo neste contexto também a escola, Gramsci acreditava que a escola deveria ter como função precípua a transformação das mentalidades na luta por hegemonia.

Para Marx, toda mudança ocorre via luta de classes. Gramsci vai além desta compreensão e completa essa teoria apresentando a cultura como o espaço em que ocorrem as lutas de classes, porém em uma perspectiva ideológica. Neste sentido, seria alcançada a revolução cultural, assim como a mudança no sistema de crenças, valores e tradições da sociedade em uma determinada época.

Gramsci visualiza a Escola Unitária como a possibilidade da construção da revolução cultural, e como consequência a formação do intelectual orgânico. A compreensão de Escola Unitária foi definida por Gramsci como uma escola destinada a trabalhadores intelectuais e manuais, vinculando o ensino técnico-científico ao saber humanista, em que todos teriam a mesma formação, seriam oferecidas as mesmas condições a todos os alunos de dirigir o Estado. Nesta perspectiva, seria formado o intelectual orgânico, na mesma medida, com um saber erudito e tecnoprofissional, comprometido com sua classe. Com esse pensamento, Gramsci entende que todos são intelectuais, uma vez que não existe atividade humana da qual se possa excluir alguma intervenção intelectual.

O grande desafio consistia em pensar uma escola socialista unitária, que articulasse o ensino técnico-científico ao saber humanista. Essa seria a possibilidade para que os trabalhadores pudessem perseguir a sua autonomia e desenvolver uma nova cultura, contrária àquela da burguesia. $\mathrm{O}$ esforço dos trabalhadores para garantir e aprofundar a cultura e para se apropriar do conhecimento traria consigo o esforço e o empenho para assegurar a sua autonomia em relação aos intelectuais da classe dominante e ao seu poder arbitrário (ROIO, 2006, p. 312).

$\mathrm{Na}$ Itália fascista, o contexto educacional da época se encontrava extremamente contrário às ideias propostas pela Escola Unitária de Gramsci. A proposição era de que houvesse um ensino tradicional de formação geral para a classe da burguesia e a uma formação técnica profissional para os trabalhadores das fábricas. 
A reforma educacional proposta por Gentile, então ministro da Instrução Pública na Itália, não possibilitava ao aluno trabalhador a opção de escolha, o qual estava destinado a uma formação voltada para o trabalho braçal, longe do ensino desinteressado. Assim, o proletariado, pertencente à planta baixa da sociedade, não tinha a menor possibilidade de chegar ao poder ou à direção do Estado. $\mathrm{O}$ controle do Estado fascista sobre a educação, no contexto da Reforma Gentile, buscava controlar as ações dos professores no ensino elementar, pois essa era à base de sustentação da educação fascista, realidade não muito diferente da prática educativa visualizada na Educação Brasileira atualmente.

A visão de Gentile era a de que a educação dos estabelecidos deveria ser diferente da educação do proletariado. Na mesma medida, ao nível médio, o fascismo destinou especial apreço, alimentando a manutenção do status social da época. Gramsci sempre chamou a atenção para o fato de que organização escolar na Itália possuía um caráter dual: o processo de formação educacional das pessoas era oferecido de acordo com sua classe social, inferiorizando as classes subalternas, que realizavam funções instrumentais, atendendo aos interesses do governo, perpetuando assim o processo de dominação.

O advento da Escola Unitária como possibilidade significa o início de novas relações entre o trabalho intelectual e trabalho industrial, não apenas na escola, mas na vida social como um todo. O princípio, por isso, irá se refletir em todos os organismos de cultura, transformandoos e emprestando-lhes um novo conteúdo (GRAMSCI, 1968). Assim, a Escola Unitária proposta por Gramsci seria a base para a luta contra a formação cultural discrepante entre as diferentes classes sociais.

A Escola Unitária pressupõe que todos os jovens tenham condições de serem governantes, ainda que em um sentido abstrato. Aqui se entrelaçam os ideais humanísticos e democráticos, e a histórica dualidade entre homem aristocrático e o homem comum se media, se supera, no homem moderno (BETTI, 1976).

Loureiro (2011) afirma que a Escola Unitária corresponde ao que hoje são os níveis primário e médio, que Gramsci classifica como sendo uma etapa básica e uma etapa média. Os três ou quatro anos iniciais seriam o momento de se construir uma ampla e necessária base de conhecimentos gerais. Na teoria da Escola Unitária, a segunda etapa responderia ao rito de passagem da escola média para a universidade. Gramsci entendia que essa etapa era marcada pela memorização. E como possibilidade de superação desta constatação, o autor propôs que a 
última etapa da escola unitária teria como tarefa principal o desenvolvimento da autonomia e da autodisciplina, assim como dos princípios fundamentais do humanismo.

Nos dias atuais, é perceptível a criação de uma cultura própria dos trabalhadores, com base em uma educação capaz de dar origem ao surgimento de intelectuais comprometidos com sua classe.

\section{Fazendo História: Percurso da Educação Profissional e Tecnológica de NíVEL MÉDIO NO BRASIL}

Em seus muitos escritos, Gramsci teorizou sobre uma realidade educacional postergada por uma formação excludente, situação que, para ele, culminava com as desigualdades sociais. Esse contexto, em muito, tem a ver com as origens da educação brasileira.

Ao analisar a história da Educação Profissional no Brasil, são claras as intenções assistencialistas, pautadas em uma educação criada para atender aos chamados desvalidos da sorte, termo utilizado por Nilo Peçanha quando da criação da primeira Escola de Aprendizes e Artífices. O Documento Base da Educação Profissional Técnica de Nível Médio Integrado ao Ensino Médio (2007) menciona que a educação básica e a educação profissional estão interligadas historicamente por uma dualidade: de um lado, um ensino geral e propedêutico; do outro, a educação profissional e tecnicista. Até o século XIX, a educação propedêutica era oferecida para as elites, voltada para a formação de futuros dirigentes, e a educação profissional para os trabalhadores de baixa renda.

No cenário recente, na escola atual, perpassada pela crise profunda da tradição cultural e da concepção da vida e do homem, observa-se um processo de progressiva degeneração: as escolas de tipo profissional, preocupadas em satisfazer interesses práticos imediatos, predominam sobre a escola formativa, imediatamente desinteressada. O aspecto mais contraditório está em que este novo tipo de escola é compreendida como democrática, quando, na realidade, não só é destinada a perpetuar as diferenças sociais como também a cristalizá-las (GRAMSCI, 2001).

No Brasil, a Rede Federal de Educação Profissional e Tecnológica teve seu início no ano de 1909, via Decreto no 7.566, expedido pelo Presidente Nilo Peçanha. As Escolas de Aprendizes e Artífices, destinadas aos pobres e aos desvalidos da sorte, foram criadas com o intuito de resolver problemas de ordem econômica e política, vigentes naquele momento histórico. "Nilo Peçanha instaurou uma rede de 19 Escolas de Aprendizes Artífices, dando 
origem à rede federal que culminou nas Escolas Técnicas e, posteriormente, nos CEFETs" (MANFREDI, 2002, p. 85).

Em 1930 as Escolas de Aprendizes e Artífices passam a ser denominadas de Liceus Industriais, contudo, a mudança de nomenclatura não mudou os objetivos das instituições. A Constituição Federal trata pela primeira vez e de forma específica sobre o ensino técnico, profissional e industrial, em 1934, mencionando as escolas vocacionais e pré-vocacionais, como um dever do Estado, a serviço da população pertencente à classe social menos favorecida (Art. 129). A Carta Magna mencionava também que tal obrigação do Estado deveria ser cumprida com a colaboração das indústrias e dos sindicatos econômicos, os quais deveriam criar, na esfera de sua especialidade, escolas de aprendizes, destinadas aos filhos de seus operários ou de seus associados.

Em 1942, surgem as Escolas Industriais e Técnicas, para substituir os Liceus, com o objetivo claro de oferecer a formação profissional em nível equivalente ao do secundário. Neste mesmo ano são criadas as chamadas Leis Orgânicas da educação nacional: Ensino Secundário, Normal e do Ensino Industrial (1942), Ensino Comercial (1943) e Ensino Primário e do Ensino Agrícola (1946). Também ocorreu a criação de entidades especializadas, como o SENAI (1942) e o SENAC (1946), assim como a transformação das chamadas escolas de aprendizes artífices em escolas técnicas.

Também no ano de 1942, o Governo Vargas, por um Decreto-Lei, estabeleceu o conceito de menor aprendiz para os efeitos da legislação profissional e, por outro Decreto-Lei, dispôs sobre a Organização da Rede Federal de Estabelecimentos de Ensino Industrial.

No Período Democrático que compreende o período de 1946 a 1963, na década de 1950, instituiu-se a equivalência entre os estudos acadêmicos e profissionalizantes. Neste momento inicia-se o processo de intensificação da profissionalização no ensino médio. Posteriormente, em 1959, as Escolas Industriais e Técnicas passaram à categoria de autarquias e foram denominadas Escolas Técnicas Federais. A rede federal de educação profissional dá início à sua configuração, em 1978, quando três unidades de escolas técnicas se transformaram em Centros Federais de Educação Tecnológica, surgindo os CEFETs do Rio de Janeiro, Paraná e Minas Gerais, posteriormente acrescidos de outras escolas que também foram elevadas à categoria de CEFETs.

Em 29 de dezembro de 2008, o presidente Luiz Inácio Lula da Silva sancionou a Lei ${ }^{\circ}$ 11.892/08, que criou 38 Institutos Federais de Educação, Ciência e Tecnologia (IFET), 
publicada no Diário Oficial da União de 30 de dezembro do mesmo ano. A mencionada lei instituiu a Rede Federal de Educação Profissional, Científica e Tecnológica no âmbito do sistema federal de ensino, vinculada ao Ministério da Educação e constituída pelas instituições, a saber: Institutos Federais de Educação, Ciência e Tecnologia - Institutos Federais; Universidade Tecnológica Federal do Paraná - UTFPR; Centros Federais de Educação Tecnológica Celso Suckow da Fonseca - CEFET-RJ e de Minas Gerais - CEFET-MG; Escolas Técnicas vinculadas às Universidades Federais (Lei 11.892/08, art. $1^{\circ}$ ).

Os Institutos Federais são instituições de educação superior, básica e profissional, pluricurriculares e multicampi, especializados na oferta de educação profissional e tecnológica nas diferentes modalidades de ensino, com base na conjugação de conhecimentos técnicos e tecnológicos com as suas práticas pedagógicas, nos termos desta Lei. (BRASIL, 2008).

Os Institutos Federais foram criados pela junção de diferentes autarquias, antigas instituições profissionais. As demais instituições que compõem a nova rede, com exceção da Universidade Tecnológica, são aquelas que decidiram pela não integração a um Instituto Federal e mantiveram a estrutura administrativa que as caracterizavam desde sua criação.

Diferente do que muitos possam imaginar, o crescente número e tipos de escolas profissionais tende a evidenciar as diferenças tradicionais; sendo que, na mesma medida, tais diferenças possibilitam a criação de estratificações internas, e faz nascer a impressão de possuir uma tendência democrática (GRAMSCI, 2001, p. 49-50).

Embora o objetivo, com esta reflexão, não seja o aprofundamento da discussão acerca do caráter segregador da história da educação profissional e tecnológica, não se pode deixar de mencionar, em um contexto comparativo, a preocupação de Gramsci a respeito da fragmentação e consolidação da educação italiana.

A crítica realizada por Gramsci ao ensino técnico italiano se dava em torno da formação especificamente técnica dos trabalhadores, impossibilitando a eles irem além do trabalho assalariado, e a consequente exploração pelo capital. Em uma perspectiva contraditória, a formação humanista era oferecida aos estabelecidos, garantindo a estes elementos para comandar, dominar e governar a sociedade capitalista, compondo os cargos na administração pública do Estado liberal/burguês.

Ora, não se trata somente da aquisição de capacidades de direção, não é a tendência a formar homens superiores que dá a referência social de um tipo de escola. A referência social é dada pelo fato de que cada grupo social tem um tipo de escola próprio, destinado a perpetuar, nestes extratos, uma determinada função tradicional, dirigente ou instrumental. A possibilidade 
de desfazer este nó, portanto, está em não multiplicar e hierarquizar os tipos de escola profissional, mas criar um tipo único de escola preparatória, seja ela primária ou média, que conduza o jovem até os complexos caminhos da escolha profissional, formando-o, durante este meio tempo, como pessoa capaz de pensar, de estudar, de dirigir ou de controlar quem dirige (GRAMSCI, 2001, p. 49).

No campo da educação Profissional e Tecnológica, os últimos vinte anos foram férteis para a política de Educação Profissional e Tecnológica no Brasil, que publicou marcos legal, visando à extinção da dualidade entre formação técnica e formação geral humanista. Entre eles ressaltam-se a Lei no 9394/96 (LDBEN); a Resolução nº 04/99; a Resolução 01/2004; o Parecer 39/2004; a Resolução n o 01/2005; o Decreto 5.154/2004; o Decreto 5.478/2005, revogado pelo Decreto 5.840/2006; o Documento Base da Educação Profissional de Nível Médio Integrado ao Ensino Médio, a Lei no 11.741/2008; e a Resolução nº 03/2008.

Contudo, a LDB se constitui como ponto de partida para as demais legislações de todas as modalidades de ensino. A Lei n ${ }^{\circ}$ 9.394/96 - Lei de Diretrizes e Bases da Educação Nacional (LDB), no seu capítulo III, trata exclusivamente da Educação Profissional. Outro importante documento normativo na Educação Profissional é a Resolução nº 04/99. A referida resolução institui as Diretrizes Curriculares Nacionais para a Educação Profissional de nível médio. No Parágrafo único do Artigo $1^{\circ}$, desta Resolução, está estipulado que a Educação Profissional, integrada às diferentes formas de educação, ao trabalho, à ciência e à tecnologia, tem por objetivo garantir ao cidadão o direito ao permanente desenvolvimento de aptidões para a vida produtiva e social. Tal legislação estabelece ainda os itens que devem contemplar um projeto pedagógico de cursos técnicos e traz como anexos os quadros das áreas profissionais e das cargas horárias mínimas para cada curso.

Observando o Decreto n ${ }^{\circ}$ 5.154/04, fica perceptível que a Educação Profissional poderá ser oferecida articulada com o ensino médio, nas formas integrada, destinada aos egressos do ensino fundamental, em que o aluno concluirá uma habilitação profissional técnica de nível médio, juntamente ao ensino médio, na mesma instituição de ensino; e concomitante, destinada àqueles que tenham concluído o ensino fundamental ou estejam cursando o ensino médio; e subsequente, oferecida somente aos egressos do ensino médio. Ainda o Artigo $7^{\circ}$ da mesma resolução institui que os diplomas de técnico de nível médio, correspondentes aos cursos realizados nos termos do Artigo $5^{\circ}$ desta Resolução, terão validade para fins de habilitação profissional e também para fins de certificação do Ensino Médio. 
O ano de 2005 se constitui como um marco para a Educação Profissional e Tecnológica: foi implantado o Programa de Integração da Educação Profissional ao Ensino Médio na Modalidade de Educação de Jovens e Adultos (PROEJA), via Decreto $n^{\circ}$ 5.478/2005. No mesmo ano, foi aprovada a Resolução 01/2005, que atualiza as Diretrizes Curriculares Nacionais definidas pelo Conselho Nacional de Educação para o Ensino Médio e para a Educação Profissional Técnica de nível médio, às disposições do Decreto no 5.154/2004. O Artigo $3^{\circ}$ desse documento apresenta a atualização da nomenclatura dos cursos e programas de Educação Profissional, no qual o termo Educação Profissional de Nível Técnico passa a denominar-se Educação Profissional Técnica de Nível Médio. No ano de 2007, é homologado o Documento Base da Educação Profissional Técnica de nível Médio Integrada ao Ensino Médio.

A Resolução 11.788/08 dispõe sobre o estágio de estudantes. O estágio nos Cursos Técnicos de Nível Médio será obrigatório quando previsto no projeto pedagógico do curso, acrescida a carga horária mínima estabelecida em cada curso. Já a Resolução 03/2008, homologada no mesmo ano, disciplina a instituição e a implantação do Catálogo Nacional de Cursos Técnicos de Nível Médio nas redes públicas e privadas de educação profissional. O catálogo define a carga horária mínima para cada um dos cursos, bem como apresenta uma breve descrição do curso, com possibilidades de temas a serem abordados, possibilidades de atuação dos profissionais formados e infraestrutura recomendada para a implantação do curso.

A partir da contextualização da educação profissional e tecnológica no Brasil, podemse perceber algumas convergências com a realidade vivenciada por Gramsci na Itália. É possível inferir que Gramsci, diante do quadro conturbado em relação à formação diferenciada para cada classe social, tenha pensado na Escola Unitária como possibilidade de superação da realidade posta.

Nesta perspectiva, o exercício a partir de agora é o de apresentar algumas semelhanças entre a Escola Unitária proposta por Gramsci e a Educação Profissional e Tecnológica na Perspectiva do PROEJA - Programa Nacional de Integração da Educação Profissional com a Educação Básica na Modalidade de Educação de Jovens e Adultos.

\section{Metodologia}

O estudo a que nos propomos realizar, busca evidenciar a relação entre o princípio educativo de Gramsci com a Educação Profissional no Ensino Médio Integrado ao Proeja. Para 
sua realização, traçamos um caminho investigativo a partir da metodologia de natureza qualitativa.

A metodologia qualitativa enfatiza o componente subjetivo do comportamento das pessoas. Bogdan e Biklen (1994), afirmam que o pesquisador, ao utilizar a abordagem qualitativa, faz uso de um conjunto de asserções que diferem das que são utilizadas quando se estuda o comportamento humano com o objetivo de descobrir fatos e causas.

Os dados foram levantados a partir da realização de uma pesquisa bibliográfica que se configura como sendo o exame de materiais de natureza diversa, que ainda não receberam um tratamento analítico, ou que podem ser reexaminado, criando novas ou interpretações complementares, atividade localização de fontes, para coletar dados gerais ou específicos a respeito de determinado tema (LAKATOS, 1992).

A característica principal da pesquisa bibliográfica é a de possibilitar ao pesquisador uma bagagem teórica variada, contribuindo para ampliar o conhecimento, de forma a fazer da pesquisa um material rico sobre o assunto, fundamentando do ponto de vista teórico o material a ser analisado.

Objetivando perceber os principais conceitos e implicações do texto da lei, fizemos uso da análise documental, que enquanto possibilidade no que se refere à pesquisa qualitativa consiste numa possibilidade a ser realizada a partir de documentos que não receberam tratamento analítico contemporâneos ou retrospectivos, considerados cientificamente autênticos, constituindo uma técnica importante na pesquisa qualitativa, seja complementando informações obtidas por outras técnicas, seja desvelando aspectos novos de um tema ou problema (LÜDKE 1986).

\section{Resultados e Discussão - A Educação Profissional e Tecnológica de nível Médio Integrada ao Ensino Médio na Perspectiva do PROEJA}

No contexto da articulação entre a proposição da escola unitária, compreendida por Gramsci como um ponto de equilíbrio no desenvolvimento das capacidades de trabalho manual, técnico e intelectual, referente ao saber desinteressado, a educação profissional e tecnológica, na perspectiva do PROEJA, no contexto da integração e articulação, proposta pelo Decreto $\mathrm{n}^{\circ}$ 5.154/2004, afirma que as instituições de ensino deverão assegurar, simultaneamente, o cumprimento das finalidades estabelecidas para a formação geral e as condições de preparação para o exercício de profissões técnicas, em seus projetos pedagógicos $\left(\S 2^{\circ}\right.$ do Artigo $4^{\circ}$ do Decreto $\left.n^{\circ} 5.154 / 2004\right)$. 
Na proposta de Gramsci (1968), a escola unitária desenvolveria a cultura geral, humanista, formativa, equilibrando, na mesma medida, o desenvolvimento das capacidades de trabalho manual, técnico, industrial e intelectual. A visão de Gramsci era de que a escola deveria pautar-se na igualdade e no estabelecimento de novas relações entre o trabalho intelectual e o trabalho industrial. Aqui residem alguns dos objetivos comuns propostos, tanto na teoria da escola unitária defendida por Gramsci, quanto na forma integrada de educação profissional na perspectiva do PROEJA, defendida e desenvolvida pelos Institutos Federais.

Loureiro (2011) afirma que o princípio unitário aplicado à escola unitária, apresentado por Gramsci, tinha por finalidade articular formação profissional e educação humanista. A escola única articula a unidade do fato educativo com o ideal de formação humana geral, vinculando a profissionalização e a formação integral, essenciais para a vida humana nos tempos modernos.

Os cursos técnicos ofertados na forma Integrada ao Ensino Médio serão oferecidos simultaneamente ao longo de todo o Ensino Médio, sendo vedada a organização desse curso em duas partes distintas. Nessa perspectiva, o projeto pedagógico, a matrícula, a matriz curricular e a certificação dos alunos são únicos, de modo a garantir o cumprimento simultâneo das finalidades estabelecidas, tanto para a Educação Profissional Técnica de Nível Médio, na perspectiva profissionalizante, quanto para o Ensino Médio Regular, com foco no ensino propedêutico.

$\mathrm{Na}$ forma integrada, as cargas horárias totais dos cursos de técnicos de nível médio, organizados nos termos do $\S 2^{\circ}$ Artigo 36 da LDB e do Inciso I, do $\S 1^{\circ}$ do Artigo $4^{\circ}$ do Decreto $\mathrm{n}^{\mathrm{o}}$ 5.154/04, caso tivessem suas cargas horárias somadas, deveriam ter, respectivamente, 3.200 horas, ou 3.400 horas ou 3.600 horas, dependendo da carga horária mínima exigida para a respectiva habilitação profissional, nos termos da Resolução CNE/CEB 4/99, a serem integralizadas em um tempo mínimo de três a quatro anos, dependendo do projeto pedagógico da instituição de ensino. A essas cargas horárias mínimas exigidas devem ser acrescidas as cargas horárias destinadas a eventuais estágios supervisionados, trabalhos de conclusão de curso ou provas finais e exames, quando previstos pelos estabelecimentos de ensino em seus projetos pedagógicos.

Um aspecto importante, alterado pelo Decreto $N^{\circ} 5.840 / 2006$, diz respeito à carga horária do curso, estabelecendo em seu artigo $4^{\circ}$ que os cursos de educação profissional técnica de nível médio do PROEJA deverão contar com carga horária mínima de duas mil e 
quatrocentas horas. No que tange à carga horária específica de cada área, o Decreto $\mathrm{N}^{\mathrm{o}}$ 5.840/2006 assegura, em seu artigo $4^{\circ}$, incisos I e II, a destinação de, no mínimo, mil e duzentas horas para a formação geral e a carga horária mínima estabelecida para a respectiva habilitação profissional técnica.

Os cursos integrados entre Ensino Médio e Educação Profissional técnica de nível médio não podem e nem devem ser entendidos como um curso que represente a somatória de dois cursos distintos, embora complementares, que possam ser desenvolvidos de forma bipolar, com uma parte de educação geral e outra de Educação Profissional. Essa foi à lógica da revogada Lei 5.692/71 e não é a lógica da atual LDB, a Lei 9.394/96, nem do Decreto $5.154 / 2004$, que rejeitam essa dicotomia entre teoria e prática, entre conhecimentos e suas aplicações.

O curso de Educação Profissional Técnica de nível médio, desenvolvido na forma integrada com o Ensino Médio, constitui-se em um curso único desde a sua concepção, inteiramente integrado e, na prática, desenvolvido como tal, desde o primeiro dia de aula até o último. Todos os componentes curriculares, na perspectiva do Ensino Médio Integrado, devem receber tratamento integrado, nos termos do projeto pedagógico da instituição de ensino. Por isso mesmo, essa nova circunstância e esse novo arranjo curricular pode possibilitar uma economia na carga horária mínima exigida, uma vez que o necessário desenvolvimento de competências cognitivas e profissionais pode ser facilitado, exatamente por essa integração curricular.

Os conteúdos que compõem o Ensino Médio atendem aos objetivos de consolidação da Educação Básica, em termos de formação geral do educando para o trabalho, e os conteúdos do Ensino Técnico objetivam a preparação para o exercício de profissões técnicas. Ambos são oferecidos simultaneamente, na forma integrada, segundo a LDB, relacionando teoria e prática no ensino de cada disciplina (Inciso IV do Artigo 35).

O advento da Escola Unitária pressupõe o início de novas relações entre o trabalho intelectual e trabalho industrial, não apenas na escola, mas em toda vida social. O princípio irá refletir em todos os organismos de cultura, transformando-os e emprestando-lhes um novo conteúdo (GRAMSCI, 1968, p. 125).

O Ensino Médio deve buscar garantir os conhecimentos básicos para uma Educação Profissional de qualidade. O Parecer 39/2004 estabelece que o Ensino Médio se constitua como a base de sustentação, indispensável em termos de educação integral do cidadão. Deve ser 
acrescentada a carga horária extra no curso técnico, nas formas concomitantes ou subsequentes, quando os alunos não demostrarem os conhecimentos básicos do Ensino Médio, para que os conteúdos sejam trabalhados.

Sob esse prisma, o Curso Técnico Integrado ao Ensino Médio, na perspectiva do PROEJA ou não, possibilita a obtenção de uma certificação em uma determinada área técnica e, ao mesmo tempo, oferece o Ensino Médio, sem comprometimento da carga horária de nenhuma das disciplinas. Nos dias atuais, com foco na teoria de Gramsci, os educandos pertencentes à planta baixa da sociedade não estariam condenados estritamente ao aprendizado técnico. A percepção é a de que a Educação Profissional e Tecnológica não compromete o ensino desinteressado, essencial para a continuidade dos estudos, ao mesmo tempo em que oferece meios para garantir sua subsistência.

[....] ensino médio integrado é aquele possível e necessário em uma realidade conjunturalmente desfavorável em que os filhos dos trabalhadores precisam obter uma profissão ainda no nível médio, não podendo adiar este projeto para o nível superior de ensino, mas que potencialize mudanças para, superando-se essa conjuntura, constituir-se em uma educação que contenha elementos de uma sociedade justa (FRIGOTTO; CIAVATTA; RAMOS, 2005, p. 44).

Fica evidente que a articulação entre o ensino médio e o ensino técnico consiste em uma necessidade social e histórica da educação, que visualiza a formação do trabalhador para além do processo de alienação. A proposta de integrar formação geral e formação técnica no ensino médio, seja ele regular ou PROEJA, visando à formação integral do educando, é agora, por determinações legais, mecanismo para superação da dualidade de classes no cenário educativo.

A crise terá uma solução que, sabiamente, evidenciaria uma escola única inicial de cultura geral, humanista, formativa, capaz de equilibrar o desenvolvimento da capacidade de trabalhar manualmente técnica ou industrialmente e o desenvolvimento das capacidades do trabalho intelectual. Neste contexto de escola única, via repetidas experiências de orientação profissional, ter-se-á uma das escolas especializadas ou direcionada ao trabalho produtivo (GRAMSCI, 1991).

Os Institutos Federais, enquanto instituição ofertante dos cursos de Ensino Médio Integrado possuem autonomia para adotar uma das formas de articulação previstas no Decreto $n^{\circ} 5.154 / 2004$. No entanto, os Institutos Federais têm, em sua lei de criação, a Lei $n^{\circ}$ 11.892/2008, como um de seus objetivos, a garantia de no mínimo 50\% (cinquenta por cento) das vagas para a Educação Profissional de Nível Médio, prioritariamente na forma de cursos integrados. Para atender ao disposto na lei acima, essas instituições, a partir de 2008, passaram 
a ministrar essa modalidade de ensino na forma integrada. De acordo com o Decreto 5.840, de 13 de julho de 2006, em seu Art. 2o, § 1o estabelece que os Institutos Federais disponibilizarão ao PROEJA a partir de 2006, no mínimo dez por cento do total das vagas de ingresso da instituição, tomando como referência o quantitativo de matrículas do ano anterior, ampliando essa oferta a partir do ano de 2007.

Gramsci direciona ao Estado a responsabilidade por promover as condições necessárias para a materialização da proposta de escola unitária. Essas condições passariam pela ampliação significativa do quadro de docentes, pela construção de prédios e instalações que acolhessem estudantes em tempo integral, dispondo de infraestrutura adequada, incluindo restaurantes, bibliotecas, dormitórios, salas de aula, entre outras instalações.

Pode-se afirmar, portanto, que há semelhanças entre a proposta de escola unitária proposta por Gramsci e a proposta de Educação Profissional e Tecnológica de Nível Médio Integrada ao Ensino Médio no Brasil, via Decreto n ${ }^{\circ}$ 5.154/2004.

\section{CONSIDERAÇões Finais}

No Brasil, assim como em vários outros países, o pensamento de Gramsci teve importantes seguidores no campo educacional. Neste cenário educacional, encontram-se referências da educação popular brasileira, como Paulo Freire e Carlos Rodrigues Brandão, Dermeval Saviani, Acácia Z. Kuenzer, Maria Aparecida C. Franco, Lucília R. de Souza Machado, Gaudêncio Frigotto, Paolo Nosella; Maria Laura P.B. Franco, Dante Henrique Moura, entre outros. Todos destacam que a educação se constitui como mecanismo de transformação humana e que a humanização seria a vocação ontológica, a qualidade de construir e construir-se. Essa vocação pode-se afirmar, em relação à formação do trabalhador, é negada na opressão, na injustiça; mas afirmada no desejo de liberdade e de justiça. Daí a necessidade de elaborar um pensamento contra hegemônico, não somente como pensamento filosófico rigorosamente articulado, mas também como prática educativa, no presente, no dia a dia das escolas, que possibilite a ascensão dos muitos explorados, ou que permita que as ideias da classe dominante sejam desconstruídas e reinventadas, em direção à construção de outra sociedade, de outro mundo possível.

Para Gramsci, a educação se caracteriza como a garantia do ponto de partida para o domínio dos demais conhecimentos e a capacidade de produzir o novo, para todos os seres humanos, independentemente de sua classe social. 
Os conceitos criados por Gramsci são utilizados em várias partes do mundo, principalmente no que se refere à formação para cidadania no interior da escola. As propostas de integração entre educação geral e educação profissional são criticadas quanto à forma de organização excludente de formação, pautadas nas lutas do proletariado contra as diversas formas de exploração a que estavam submetidos.

$\mathrm{Na}$ contemporaneidade, é essencial analisar a proposta de escola unitária em Gramsci, diante de debates e discussões sobre as várias reformas educacionais ocorridas no ensino brasileiro, consequência das políticas neoliberais. Para além do desenvolvimento de um processo de alienação, o desenvolvimento tecnológico, que exige mão de obra qualificada, exige, na mesma medida, trabalhadores educados para a dinâmica flexível da esfera produtiva.

Fica perceptível, portanto, que, independentemente do projeto pedagógico do curso, da legislação que o rege, ou mesmo de sua modalidade de ensino, este pode se aproximar da proposta de Gramsci, dependendo, para isso, de sua abordagem na prática pedagógica. Na perspectiva do Ensino Médio, no Brasil, mesmo diante da existência de uma legislação que fixa o trabalho vinculado à autonomia e à cidadania, ainda é comum encontrar práticas vinculadas a conteúdos rígidos e decoráveis, que formam um indivíduo tecnicista, voltado unicamente para o trabalho mecânico. Por outro lado, também é possível encontrar cursos técnicos, elaborados para sustentar o mercado de trabalho e qualificar o indivíduo, de modo que este possa desenvolver seu ofício junto a máquinas, e transpor tais objetivos, tornando-se, através da formação, cidadãos conscientes da realidade em que estão inseridos, munidos de ferramentas para modificar sua situação, independentemente da classe a que pertencem.

Nesta perspectiva, no que se refere à Educação Profissional e Tecnológica, defender e buscar semelhanças com a proposta de escola unitária de Gramsci significa se posicionar contra propostas e políticas educacionais que pretendam, apesar do discurso muitas vezes sedutor, manter o quadro estrutural de subordinação do trabalho ao capital. Pode-se afirmar que Gramsci e seus seguidores visualizaram no trabalho, a partir da educação, a humanização do homem. Os pressupostos de Gramsci encontrados na educação, tanto no contexto da Escola Unitária, como da Educação Profissional e Tecnológica, são a própria luta pela superação da sociedade de classes. Assim, é possível pensar o ser humano em construção como criador de uma sociedade livre das amarras da alienação. A implantação dos cursos técnicos integrados e oferecidos, tanto no ensino regular como no PROEJA, em uma perspectiva de inclusão do trabalhador, é um dos 
avanços desenvolvidos pela educação brasileira rumo à extinção da desigualdade de classes e da própria dualidade na formação dentro das escolas do país.

\section{REFERÊNCIAS BIBLIOGRÁFICAS}

BETTI, Gianni. Escuela, educación y pedagogia em Gramsci. Barcelona, Ediciones Martinez Roca, 1981.

BRANDÃO, Carlos Rodrigues; CHAUÍ, Marilena de Souza; FREIRE, Paulo. O educador: vida e morte. Rio de Janeiro: Graal, 1982.

BOGDAN, Robert; BLIKEN, Sari Knopp. Investigação qualitativa em educação, uma introdução à teoria e aos métodos. Tradução: Maria João Álvares, Sara Bahia dos Santos, Telmo Mourinho Baptista. Coleção Ciências da Educação. Porto: Porto Editora, 1994.

BRASIL. Lei no 9.394, de 20 de dezembro de 1996. Diário Oficial da União, Brasília, 23 dez. 1996.

BRASIL. Conselho Nacional de Educação. Parecer CNE/CEB no 11/2000. Diretrizes Curriculares para a Educação de Jovens e Adultos. Brasília, MEC, maio 2000.

BRASIL. Ministério da Educação. Programa de Integração da Educação Profissional ao Ensino Médio na Modalidade de Educação de Jovens e Adultos - PROEJA: Documento Base. Brasília: MEC, fev. 2006.

BRASIL. Conselho Nacional de Educação. Câmara da Educação Básica. Resolução no 04, de 04 de dezembro de 1999.

BRASIL. Conselho Nacional de Educação. Conselho Pleno. Resolução nº 01, de 17 de junho de 2004.

BRASIL. Conselho Nacional de Educação. Câmara da Educação Básica. Parecer n 39, de 08 de dezembro de 2004.

BRASIL. Presidência da República. Decreto no 5.154, de 23 de julho de 2004. Diário Oficial da União, Brasília, 26 jul. 2004.

BRASIL. Presidência da República. Decreto no 5.478, de 24 de junho de 2005. Revogado pelo Decreto 5.840, de 13 de julho de 2006. Diário Oficial da União, Brasília, 27 jun. 2005.

BRASIL. Presidência da República. Decreto no 5.840, de 13 de julho de 2006. Diário Oficial da União, Brasília, 14 jul. 2006.

BRASIL. Presidência da República. Lei Federal no 11.741, de 16 de julho de 2008. Diário Oficial da União, Brasília, 17 jul. 2008.

BRASIL. Conselho Nacional de Educação. Câmara da Educação Básica. Resolução no 03/2008, de 09 de julho de 2008.

BRASIL. Presidência da República. Projeto de Lei Federal n 1.209, de 29 de abril de 2011. 
FRIGOTTO, Gaudêncio; CIAVATTA, Maria; RAMOS, Marise. (Org.). Ensino Médio integrado: concepções e contradições. São Paulo: Cortez, 2005.

GADOTTI, Moacir. Histórias das ideias pedagógicas. São Paulo: Ática, 1999.

GRAMSCI, Antonio. Os intelectuais e a organização da cultura. Rio de Janeiro: Civilização Brasileira, 1968.

LAKATOS, Maria Eva; MARCONI, Maria de Andrade. Metodologia do Trabalho Científico. 4. ed. revista e ampliada. São Paulo: Atlas, 1992.

LOUREIRO, Bruno. Escola unitária e hegemonia: a indissociabilidade entre educação e política no pensamento de Antonio Gramsci. Educação Unisinos, v. 15, № 1, 2011.

Disponível em: http://www.unisinos.br/revistas/index.php/educacao/article/view/457. Acesso em: 18 jun. 2013.

LÜDKE, Menga, ANDRÉ, Marli. Pesquisa em educação: abordagens qualitativas. São Paulo: EPU, 1986.

MANACORDA, Mario Alighiero. O princípio educativo em Gramsci. Porto Alegre: Artes Médicas. 1990.

MANFREDI, Silvia. Maria. A educação profissional no Brasil. São Paulo: Cortez, 2002.

ROIO, Marcos Del. Gramsci e a educação do educador. Caderno Cedes, Campinas, v. 26, n.70, p. 311-328, set./dez.2006. Disponível em: http://www.cedes.unicamp.br. Acesso em: 24 jun 2013. 